\title{
Gestão de desastres e política de assistência social
}

\author{
Rúbia dos Santos
}

Fundação Universidade Regional de Blumenau (FURB)

\section{Gestão de desastres e política de assistência social}

Resumo: Neste artigo reflete-se sobre o sistema de gestão de risco no município de Blumenau, em Santa Catarina, através das ações desenvolvidas pela Política de Assistência Social. Usou-se uma abordagem plural que articulou a análise documentária a técnicas qualitativas, como a observação participante. Foram examinados estudos já realizados sobre o risco como um processo construído que contribui com a intensificação dos desastres socioambientais na região. Constatou-se que a falta de um planejamento integrado e participativo resulta em fragmentação das ações, ausência de interdisciplinaridade e descompasso entre gestores, técnicos e afetados. Palavras-chave: Desastres socioambientais. Política de Assistência Social. Serviço Social.

\section{Management of Disasters and Social Assistance Policy}

Abstract: This article reflects on the risk management system in the municipality of Blumenau, Santa Catarina, through actions undertaken by the Social Assistance Policy. It used a plural approach that articulated document analysis to qualitative techniques, such as participant observation. Previously conducted studies about risk were examined as a constructed process that contributed to the intensification of socio-environmental disasters in the region. It found that the lack of integrated and participative planning results in fragmentation of actions, an absence of interdisciplinarity and a gap between administrators, technicians and those affected.

Keywords: Socio-environmental disasters. Social Assistance Policy. Social Work. 


\section{Introdução}

Este artigo tem por finalidade refletir sobre o sistema de gestão de risco em um município catarinense e as ações da Política de Assistência Social nesse contexto. Situa o papel desenvolvido por essa política pública que, juntamente com a Defesa Civil, assume as responsabilidades de atendimento em momentos de emergência e pós-impacto.

Busca demonstrar que os desastres constituem-se como processos sociais e refletem diretamente o modelo de desenvolvimento adotado pela região, o grau de preparação da sociedade, a rapidez e a agilidade nas repostas e a forma como se estabelece a reconstrução.

De acordo com o Programa das Nações Unidas para o Desenvolvimento (PNUD, 2004), em seu documento La Reducción de Riesgos de Desastres - Un Desafio para el Desarrollo, Informe Mundial, cerca de $75 \%$ da população mundial vive em zonas que, ao menos uma vez, foram afetadas por um desastre natural: terremotos, ciclones tropicais, inundações e secas. Esses dados referem-se ao período compreendido entre 1980 a 2000 , do qual resultaram mais de 184 mortes diárias e um significativo contingente de desabrigados em várias partes do globo.

Barcelos e Oliveira (2010) destacam que nos estudos apresentados pelo IBGE pode-se verificar que o risco ambiental não se distribui de forma aleatória entre os diferentes grupos sociais, mas obedece aos padrões de desigualdade e segregação social que marcam a estruturação das cidades. Assim, constata-se que as populações menos favorecidas, por características de renda, escolaridade, cor, gênero, que residem ou utilizam os territórios de maior vulnerabilidade ambiental, encontram-se mais expostas ao risco de desastres, já que se sobrepõem as vulnerabilidades sociais à exposição a riscos ambientais.

Os estudos existentes, notadamente os pesquisados para estas reflexões, observam que, quanto mais vulnerável uma população, maiores serão as consequências e a devastação no período posterior ao desastre. Essa realidade vem sendo profundamente sentida na região do Vale do Itajaí, no estado de Santa Catarina, destacadamente no município de Blumenau, onde as ocorrências remontam ao século passado e acompanham o desenvolvimento socioeconômico da região.

Por que, apesar de conviver há 150 anos com situações de desastres, estes continuam intensificando-se e tornando-se cada vez mais devastadores?

\section{Metodologia}

Em busca de respostas, foram feitos estudos sobre essas situações, partindo-se de pesquisa bibliográfica e documental, de análise dos estudos já exis- tentes em Blumenau, como por exemplo os de Mattedi $(1999,2000,2009)$ que identificam o tratamento político dado às situações de emergência naquele município. Além disso, acompanhou-se os desdobramentos do desastre ocorrido em 2008, através de observação participante, visitas aos abrigos, diálogos com afetados e contato com profissionais tanto do Serviço Social quanto da Defesa Civil. Foi este o caminho que possibilitou a construção das reflexões e dos dados apresentados nesta pesquisa, com o intuito de poder identificar tendências e possibilidades capazes de provocar revisões e mudanças nessas situações.

\section{Desastres socioambientais}

Corroborando a ideia de que pobreza e desastres são variáveis intrínsecas, Mattedi (1999) reforça que seria um equívoco analítico supor que a formação de situações de emergência manifesta-se em todas as regiões da mesma maneira e que todos os setores sociais são atingidos da mesma forma. Pois, mais de 95\% das vítimas e $75 \%$ das perdas econômicas provocadas por essas situações encontram-se em países menos desenvolvidos. Para o autor, os dados disponíveis atualmente indicam que determinados grupos sociais são mais vulneráveis que outros e, por isso, os desastres não podem ser examinados isoladamente, mas sim nos contextos que definem como as populações compreendem e reagem a esses fenômenos. As ações parciais como resposta aos desastres contribuem para a ocupação das áreas de risco - também descritas pelo autor como ciclo do desastre: desastres-dano-reparação-desastres -, tornando os indivíduos e as comunidades marginalizadas incapazes de gerar mudanças em suas condições de vida. Para ele (1999), a vulnerabilidade define-se por aumento da população, desigualdades na distribuição dos recursos, marginalização de grupos específicos e a crescente interdependência global.

É a combinação de fatores naturais e sociais que definem o desastre. Ou, mais precisamente, são as características físicas do evento que determinam a probabilidade de ocorrência do fenômeno e são as condições sociais de vulnerabilidade que determinam a severidade do impacto.

Outro aspecto, apontado pelo autor, refere-se ao "princípio de continuidade" que considera a passagem das condições de vulnerabilidade pré-impacto para condições de destruição pós-impacto. $\mathrm{O}$ desastre só desencadeia a destruição incubada socialmente e que é construída pela incapacidade cognitiva da população de conceber adequadamente o problema ou de agir política e tecnicamente na confrontação (MATTEDI, 2009).

O Brasil em 2008 ocupava a décima terceira colocação entre os países mais afetados por catástro- 
fes naturais, com pelo menos dois milhões de pessoas atingidas. Os fenômenos mais recorrentes encontram-se atrelados, principalmente, aos processos atmosféricos, como as precipitações pluviométricas. Todavia, sendo o Brasil um dos países mais atingidos por esses fenômenos

[...] por que ainda persiste certa leniência quanto às ações do poder público no que concerne à gestão dos riscos naturais? Ainda persiste um mito de que no Brasil não ocorrem desastres naturais? Aliás, existe gestão de riscos naturais no Brasil? (ALMEIDA; PASCOALINO, 2009, p. 2).

A prática da gestão de risco é inerente ao surgimento dos povos que desenvolveram formas de conviver com a natureza e seus eventos naturais. No entanto, os impactos destrutivos gerados pela ação antrópica sobre o funcionamento dos sistemas ecossociais ${ }^{1}$, ao longo da história da humanidade, desencadearam uma crise socioambiental planetária vivenciada na contemporaneidade.

Atualmente, nos países desenvolvidos, a gestão de risco de desastres socioambientais recobre uma série de políticas e medidas incluindo de forma genérica a proteção, a prevenção ou a previsão dos riscos. De acordo com Almeida e Pascoalino (2009), no século 19, a proteção "ativa", baseada no princípio da gestão integrada na escala da bacia hidrográfica, presumia uma erradicação de riscos naturais. Já no século 20, onde os bens ameaçados cresceram tanto em volume quanto em valor e os impactos sociais foram mais evidenciados, houve uma tomada de consciência da ineficácia e insuficiência das formas de proteção, possibilitando-se, assim, a incorporação de novas medidas de gestão, tais como: a) prevenção e regulamentação da ocupação do solo, informações das comunidades em risco, retornos de experiência; b) previsão com sistemas de monitoramento e alerta, mitigação, organização de emergência e gestão de crise, reparações e cobertura de seguros.

No que tange à gestão de risco no Brasil, apenas nos últimos cinco anos percebe-se maiores preocupações com o tripé proteção, previsão e prevenção. No entanto, o que efetivamente ocorreu foi uma urgente gestão de crise, ou seja, ações engendradas após a ocorrência dos impactos. Pouco se avançou no sentido de criar uma cultura de risco pautada no conhecimento, na consciência e na memória do risco (ALMEIDA; PASCOALINO, 2009).

Mesmo considerando os esforços para difundir uma cultura dos desastres ${ }^{2}$ no Brasil a partir da criação da Política Nacional de Defesa Civil, constatase que não há uma gestão de risco e sim uma gestão de crise, evidenciada pelos desastres socioambientais cada vez mais recorrentes e devastadores, especial- mente nas comunidades mais vulneráveis ao risco, o que denota o colapso desta forma de gestão.

\section{Blumenau e o risco socialmente construído: características socioambientais e problemá- tica urbana}

No nordeste de Santa Catarina, encontra-se o município de Blumenau. Conforme o Instituto de Pesquisa da População Urbana de Blumenau (IPPUB), a cidade possui 301 mil habitantes, destes, $51 \%$ são mulheres e $49 \%$ homens com expectativa de vida até 72 anos. Esta área está dividida em 35 bairros e dois distritos, (Vila Itoupava e Garcia). A maioria das famílias é migrante no município, totalizando 50,37\%, contra $49,63 \%$ de blumenauenses.

Considerada polo industrial de grande movimentação financeira, teve seu desenvolvimento econômico atrelado ao aprofundamento das desigualdades sociais. A ocupação ilegal acompanhou o crescimento demográfico. Na década de 1970, houve um intenso fluxo migratório que não foi acompanhado por uma política habitacional condizente. Já, a partir da década de 1990, o processo de reestruturação produtiva das empresas, que adotaram a flexibilização, a terceirização e investiram em automação, intensificou o desemprego em massa e a precarização das relações trabalhistas, aprofundando a problemática local: "A exclusão socioeconômica gerou, assim, a exclusão socioespacial, caracterizando uma crise socioambiental" (SIEBERT, 2009, p. 48).

No que diz respeito às questões geográficas, a cidade já é considerada vulnerável por sua localização. A bacia hidrográfica do Rio Itajaí ${ }^{3}$ tem área total de 15 mil km² e corresponde a $16,15 \%$ do território catarinense. $\mathrm{O}$ relevo da bacia indica grande complexidade geoecológica, susceptibilidade à dinâmica de processos erosivos e fragilidade ambiental. Nessa bacia, vivem atualmente cerca de 1.150.mil pessoas, distribuídas em 49 municípios (AUMOND et al., 2009).

Nesse horizonte pode-se perceber que os fatores geográficos, atrelados ao modelo de desenvolvimento socioeconomico adotado pela região e a destruição gradativa do meio ambiente, tornam Blumenau uma área suscetível ao risco de desastres.

Desde sua colonização, no início do século 19 , Blumenau vem sofrendo uma série de mudanças, a começar pela estratégia do governo brasileiro para estabelecer comunicação entre o litoral e o planalto incentivando a concentração de grandes contingentes imigratórios. A ideia era estabelecer, nas áreas de florestas das províncias meridionais, colonos que fossem pequenos proprietários, que utilizassem mão de obra familiar, para não competir na criação de gado (FRANK, 2003). 
A colônia de Blumenau foi estabelecida a partir de 1850 e o processo de colonização é acompanhado pela história das enchentes. Foram 69 impactos que atingiram a cidade desde então. De acordo com Mattedi (2000), o que se pode notar é que o problema das enchentes no Vale do Itajaí engendra duas questões interligadas: por um lado, a existência de uma longa experiência do convívio com o problema e, por outro, uma tendência de agravamento deste com a intensificação da destruição ambiental nas últimas décadas.

O primeiro registro de enchente remonta ao ano de 1852 e, desde então, a problemática vem se aprofundando. De todos os impactos, o de maiores proporções foi o ocorrido em novembro de 2008 a partir de uma combinação de cheias, enchentes e deslizamentos (escorregamentos), sendo estes últimos os principais responsáveis pelas mortes ocorridas.

Essa combinação de fatores teve consequências drásticas para a região. Santa Catarina registrou números alarmantes: 63 municípios decretaram situação de emergência e 14, estado de calamidade públi$\mathrm{ca}^{4}$. A Defesa Civil registrou 78.656 desalojados e desabrigados, 135 mortes e 1,5 milhões de afetados pelas consequências das chuvas.

Em Blumenau, 103 mil pessoas foram afetadas: 5.209 desabrigadas (perderam suas casas); 25 mil desalojadas; 2.382 feridas ou gravemente feridas e 24 morreram. Mais de 18 mil casas, 38 unidades de saúde, 61 unidades de ensino, centenas de quilômetros de rodovias e pavimentações foram danificadas. Após o desastre muitas ações e intervenções foram realizadas. A Defesa Civil, a partir do aeroporto de Navegantes 5 "resgatou 1.249 pessoas no período de 24 de novembro a 6 de dezembro de 2008, com 546 horas de voo". Foram utilizadas 21 aeronaves, sendo 20 helicópteros e um avião, para socorrer as vítimas (SEVEGNANI et al., 2009, p. 116).

No início do desastre, o fornecimento de energia elétrica e de água foi interrompido, somente quatro dias após esse serviço foi aos poucos restabelecido. A comunicação, por telefone celular ou fixo, também ficou interrompida. $\mathrm{O}$ transporte coletivo foi totalmente paralisado nos primeiros dias do desastre, devido ao alagamento dos terminais. Houve interrupção no fornecimento de gás natural em razão do rompimento dos dutos no trecho que atravessa o Vale do Itajaí. O ensino público foi totalmente paralisado durante a semana do evento, seguido do encerramento antecipado do ano letivo. A rede de assistência à saúde suspendeu suas atividades rotineiras para focar no atendimento emergencial (SEVEGNANI et al., 2009).

Diante da tragédia que se abateu na região, foi decretada situação de calamidade pública e a Defesa Civil $^{6}$ municipal assumiu as ações no pós-desastre. Uma das primeiras ações foi recorrer à presença das Forças Armadas para ações de resposta (res- gate e reabilitação), sinalizando a vulnerabilidade institucional local. Este tipo de intervenção militarizada remete à reflexão sobre as relações estabelecidas. Há, por parte dos representantes das Forças Armadas, uma forte resistência ao diálogo e à negociação, sobretudo com "civis". Preparados para atuar em momentos de guerras e conflitos, com autoridade e moralidade, sua hierarquização reflete-se na forma verticalizada de comandar as ações, relegando as políticas públicas locais a meros coadjuvantes.

Por outro lado, os profissionais que compõem a Defesa Civil, oriundos das corporações militares, não abrem mão de sua visão de mundo. Conforme destaca Valêncio et al. (2009) o "outro" do policial militar é o elemento suspeito, que age pressupostamente em conflito com a lei. Já o "outro" do bombeiro, é a vítima de um sinistro pedindo socorro. O "outro" para as Forças Armadas é o inimigo, visto como um agente ameaçador externo. Em todos estes casos, o "outro" não é visto como um cidadão, ou seja, alguém com direitos legítimos que requerem o estabelecimento de relações de igualdade. Desta forma, na prática, essas visões de mundo manifestam-se remetendo à necessidade de reconstruí-las sob novas bases.

Após análise das atividades realizadas pelos órgãos municipais, Negredo (2009) constata que diversos fatores contribuíram para o mau desempenho dos representantes da Defesa Civil: a) o desconhecimento da classe política e da comunidade sobre as atividades do órgão; b) a inexistência de quadro permanente de funcionários (90\% do quadro é composto por militares estaduais, o qual é integralmente substituído a cada troca de governo); c) a interrupção sistemática da estrutura estadual da Defesa Civil; d) a concepção popular de que seja um orgão meramente assistencial (por desenvolver atividades quase que exclusivamente no pós-desastre); e) a administração isolada e desintegrada; e f) a falta de projetos (as ações centramse no pós-desastre, com pouca atenção às fases de prevenção e preparação para os desastres).

Estas questões trazem à tona a necessidade de reformulação do compromisso da Defesa Civil para com a sociedade. Esse órgão, de importância inquestionável, precisa rever os princípios do arcabouço institucional, incorporando discussões relacionadas aos direitos humanos e atuando de forma integrada com a Política Nacional de Assistência Social.

\section{A Assistência Social e os afetados: das áreas de risco para o abrigo temporário e a (re)ocu- pação das moradias de risco}

Como política integradora da Seguridade Social, a Assistência Social possui um caráter de política de proteção social articulada a outras políticas, voltadas à garantia de direitos e de condições dignas de vida. 
Atualmente, pode-se considerar que os desastres socioambientais constituem-se como ameaças à vida social, especialmente às populações que vivenciam a exclusão socioespacial e a socioeconômica, que são, majoritariamente, as mais afetadas nesses contextos. Por isso, o risco de desastres deve ser pensado e gestado por um conjunto de políticas públicas e instituições e não apenas pela Defesa Civil. A proteção social deve ultrapassar o entendimento mono, buscando uma visão transdisciplinar que possa incorporar a prevenção aos riscos em todos os aspectos da vida social.

É neste contexto, que se busca dimensionar a importância da Política de Assistência Social no atendimento às famílias e aos indivíduos em situação de risco. Por atuar diretamente com as expressões da questão social, esta política desenvolve ações imprescindíveis, relacionadas aos desastres socioambientais: a) a preparação, ou pré-impacto, refere-se à atuação direta junto a indivíduos e famílias em situação de risco e vulnerabilidade social, que habitam áreas de risco, vivenciam situações de pobreza e exclusão socioeconômica e socioespacial, sendo este o público em potencial dos desastres; b) ruptura/emergência, ocorre durante o impacto, trata-se da responsabilização pelo acolhimento dos afetados, por sua inserção nos abrigos, da gestão do abrigo, do gerenciamento e da distribuição de benefícios, entre outras ações; c) recuperação, ou pós-impacto, relaciona-se à garantia dos meios de manutenção dos afetados nos

... os desastres

socioambientais constituem-se como ameaças à vida social, especialmente às populações que vivenciam a exclusão socioespacial e a socioeconômica, que são, majoritariamente, as mais afetadas nestes contextos. abrigos ou do retorno às moradias que ainda estiverem em condições de habitabilidade, acompanha o encaminhamento às moradias populares, defende a participação da população no processo decisório sobre a reconstrução das cidades, orienta sobre o acesso aos benefícios contínuos, entre outras.

Essas são apenas algumas das inúmeras ações desenvolvidas pela Política de Assistência Social nos contextos de crise. No entanto, observa-se que essas ações restringem-se ao momento do desastre e ao pós-impacto. Muito pouco vem sendo realizado de forma pró-ativa na gestão de risco, porque não há entendimento do papel desta política nesse contexto. Mesmo com a reformulação, aprovada em 2004, percebe-se que as ações desenvolvidas têm sido meramente assistenciais e paliativas, não havendo uma integração com a rede de atendimento do município. Em especial, nas situações de desas- tres, a política não dá conta de assumir com a responsabilidade que lhes é designada.

Não há, espantosamente, em uma cidade que convive há 150 anos com situações de desastres, uma sistemática de atuação no sentido de prevenir ou gestar meios de minimizar os riscos. Na realidade, não há um sistema de gestão de risco consolidado, apenas intervenções esparsas que não convergem. Neste emaranhado de indefinições de papéis e falta de clareza na forma de agir em situações de crise, encontra-se a Política de Assistência Social que, absorvida pela intervenção militarizada e hierárquica Exército, Corpo de Bombeiros e Defesa Civil), não consegue desempenhar e executar ações condizentes com o que preconiza a Política Nacional.

No impacto de 2008, além de todas essas dificuldades, a acolhida dos afetados também foi problemática. Para atendê-los, foram dispostos abrigos por região: na região central, 10 abrigos acolheram 560 pessoas; na região sul, 20 abrigos acolheram 1708; na região norte foram 12 abrigos para 608 atendidos, totalizando 4.456 pessoas abrigadas(ANGIONI, SAMAGAIA, 2009).

Os acolhimentos foram improvisados em escolas, igrejas, clubes, com o cuidado de abrigar as famílias em locais próximos à sua comunidade. Os abrigos foram coordenados por profissionais vinculados à Secretaria Municipal de Assistência Social e da Criança e do Adolescente (Semascri), sobre a qual recaíram inúmeras críticas. De acordo com Angioni e Samagaia (2009), a Secretaria foi incumbida de responder a todas as situações de fragilidade social decorrentes da situação sem uma clara articulação com as políticas de saúde, educação e habitação, evidenciando um problema de gestão, também, no atendimento governamental ao desastre.

Além da fragmentação das ações, da falta de direcionamento e organização governamental, o cancelamento dos benefícios de transferência de renda ${ }^{7}$ e de serviços de atendimento à população foram considerados outro grande problema em relação às vitimas. Nos abrigos, a situação foi caótica. Todos foram submetidos a regras de um "manual dos abrigos" (sobre divisão de tarefas, horários de entrada e saída, de dormir e de acordar) que sequer foi discutido com a população usuária:

Não se buscou, de modo algum, a participação dos atingidos na elaboração dessas propostas, levan- 
do-os a receber tais regras como imposições e terem, desta forma, dificuldades de tomá-las como normas cotidianas para a organização de suas próprias vidas (ANGIONI; SAMAGAIA, 2009, p. 142).

De acordo com as autoras, a falta de participação dos atingidos na elaboração e na execução das ações de enfrentamento ao desastre, "causou uma situação de insegurança social, com falta de credibilidade nas ações governamentais e gerou como consequência última, a organização dos próprios atingidos" (ANGIONI, SAMAGAIA, 2009, p. 142).

Aqui, novamente, remete-se à forma como os afetados são vistos pelos órgãos públicos, o que se reflete também na sua tratativa. Mais do que ausência de segurança e de confiabilidade da população nos órgãos de emergência, há a ausência de cidadania, isto é, da possibilidade de crer no outro como representante de instituições, com deveres perante o afetado (VALENCIO et al., 2009).

Foram inúmeros os conflitos nos abrigos. A falta de diálogo com a população usuária e a gestão centralizadora levaram à criação do Movimento do Atingidos pelo Desastre (MAD), que passou a lutar por direitos que estavam sendo violados.

Nas reuniões do MAD, o descontentamento era evidente. As famílias não eram ouvidas e os soldados do Exército lidaram com a situação como se estivessem em verdadeiros campos de guerra. Em um dos encontros ${ }^{8}$, um pai de família relatou que não pôde acessar leite na cozinha, para sua filha ainda bebê que sentia fome, a partir do "toque de recolher" que era às 22 horas. Os horários de alimentação eram controlados, entradas e saídas também. Famílias inteiras ficaram em salas de aula de escolas, onde não havia a mínima privacidade.

Evidencia-se um ordenamento institucional perverso, onde desencadeiam práticas arrogantes de agentes públicos, incluindo as da Defesa Civil, que, de acordo com Valencio et al. (2009), confundem a recomendação de operar com impessoalidade, passando a operar com insensibilidade ao drama coletivo e individual de desalojados, virando, por vezes, as costas às suas obrigações.

Neste contexto, os afetados transitam entre as categorias de desabrigados, desalojados e abandonados. De cidadãos de direitos passam a ser "dependentes do Estado", e as velhas práticas tutelares, controladoras e paternalistas voltam à tona. No entender de Rizek (2002 apud VALÊNCIO, 2009, p. 14, grifos do autor):

Campeiam a intolerância, a discriminação e o preconceito contra os setores empobrecidos do país ao ponto de elites e servidores públicos sentiremse livres para propagar seus próprios parâmetros de justiça e incitarem violência aos princípios cons- titucionais, retalhando a nação entre os que devem ser tratados com civilidade e os 'matáveis'.

Assim, o provisório vira permanente e o afetado, dependente. Foram construídos galpões com divisórias para abrigar as famílias, onde, decorridos dois anos do desastre, ainda encontravam-se, aproximadamente, 260 famílias, cerca de 2 mil pessoas, vivendo em péssimas condições, sem privacidade, utilizando banheiros coletivos e lidando com as frustrações da falta de um lar?.

Somente no ano de 2011, a Prefeitura Municipal, por intermédio do Programa Minha Casa Minha Vida, repassou à população 580 apartamentos construídos no bairro Progresso. Destes, apenas 220 unidades destinaram-se aos afetados, o restante foi repassado a famílias de baixa renda que também aguardavam na lista de espera. Muitas famílias permanecem no abrigo que ainda está ativo.

Insatisfeitas com a morosidade das ações estatais e recusando-se a viver nos abrigos, 24 famílias começaram um processo de ocupação de uma área pública que estava sem utilização e reergueram suas casas. Essas ocupações foram motivadas pelos integrantes do MAD, o qual luta judicialmente pela permanência ali, até que outra solução seja apresentada. Essas famílias, apesar de estarem habitando uma área não considerada de risco, sofrem a angústia da ordem de despejo que está em tramitação na Justiça.

Por outro lado, a maioria dos afetados retornou a morar nas áreas de risco, reocupando suas antigas moradias.

Analisando o processo histórico local, sabe-se que o desastre é uma tragédia anunciada e que poderá ocorrer a qualquer momento, castigando, novamente, estas mesmas famílias que voltaram a habitar áreas de risco. Mas o que fazer se o mercado imobiliário não permite que ocupem áreas seguras? Se os afetados ficam a mercê da morosidade do poder público?

$\mathrm{O}$ desastre de 2008 trouxe à tona o colapso do modelo de gestão de risco até então utilizado. Como dito anteriormente, a intervenção militarizada sobrepôs-se às ações das diversas políticas públicas e muitos profissionais ficaram reféns desta forma de conduta. No que se refere aos profissionais do Serviço Social, sua experiência nos abrigos refletiu projetos societários e bases ético-políticas diferenciados.

O posicionamento e os compromissos políticos da categoria profissional dos assistentes sociais em relação a determinados valores e princípios, assentados em referências teóricas que expressam uma determinada concepção de homem e de sociedade, traduzem-se em normas e diretrizes (Código de Ética) para a atuação profissional. No entanto, nem sempre este código é o balizador da prática profissional. Entram em jogo outros fatores que influenciam na intervenção. 
$\mathrm{O}$ assistente social, muitas vezes, em momentos de crise como este em estudo, encontra-se em meio a um emaranhado de indefinições quanto aos papéis a serem desempenhados, quanto às ações políticas e as formas de atuar. Em alguns abrigos, o assistente social comportou-se como mero executor de tarefas, seguindo as orientações da Defesa Civil e do Exército, com regras impostas, horários determinados e coordenador indicado pelo gestor. Nesses espaços, os conflitos foram constantes, gerando insatisfação por parte dos afetados e situações difíceis de serem administradas. De acordo com Valencio (2009), devido à insatisfação dos abrigados com as normas impostas e o risco de que conflitos com gestores e entre o grupo, o abrigo passa a ser visto pela Defesa Civil como de difícil administração.

Por outro lado, assistentes sociais que tiveram uma postura crítica frente à realidade conseguiram intermediar as relações entre afetados, Defesa Civil e Exército, construindo regras coletivas, dialogando sobre os horários, divisão de tarefas e elegendo o coordenador do abrigo. Nestes espaços, a auto-organização dos afetados contribuiu na condução dos trabalhos e possibilitou o exercício democrático na tomada de decisões.

Os fatores determinantes para a conduta dos profissionais de Serviço Social são de diversas ordens. Em alguns casos, a insegurança dos cargos comissionados torna os profissionais reféns das "ordens" do gestor. Por consequência, a falta de uma leitura crítica da realidade traduz-se na culpabilização das famílias pela sua condição, na ausência de diálogo com a população afetada e no não reconhecimento do código de ética profissional como balizador da prática.

De acordo com Iamamoto (2002), o maior desafio da categoria na atualidade, no sentido de efetivação do projeto, é torná-lo um guia efetivo para o exercício profissional e consolidá-lo por meio de sua implantação efetiva. Para tanto, é necessário articular as dimensões ético-políticas, acadêmicas e legais que lhe atribuem sustentação com a realidade do trabalho profissional que se materializa.

\section{Reflexões finais}

Todas estas dificuldades processam-se pela posição periférica da questão socioambiental nos programas governamentais em todos os níveis, pela alta suscetibilidade às flutuações políticoinstitucionais, pela hegemonia de uma cultura política conservadora e clientelística, pela carência de financiamento para pesquisas integradas interdisciplinares, e pelo baixo nível de interação entre as instituições de gestão e de pesquisa científico-tecnológica e as comunidades locais (REBOUÇAS; FILARDI; VIEIRA, 2006).
A recorrência dos desastres, ao invés de ser foco de reflexão dos gestores, com intuito de analisar erros e insuficiências transformando-os em aprendizado social, torna-se, muitas vezes, palco de exibição pública e disputa de poder. Para os políticos, a prevenção não dá marketing, gerando o descaso com a situação, o que pode ser comprovado pelos dados socioculturais e sociodemográficos da região. As ações engendradas visam mais conter os ânimos, reestabelecer a ordem, retomando a normalidade anterior. No entanto, cabe refletir sobre o conceito de normalidade que possa ser instaurado. Se as comunidades afetadas são consideradas áreas de risco, como reestabelecer a normalidade? Seria retomar os padrões anteriores ao desastre e reestabelecer as famílias nessas áreas? Sem que haja uma mudança estrutural que envolva todas as áreas e as Políticas Públicas? Mas se o objetivo fosse minimizar os riscos, o desastre deveria ser um ponto de partida, um reordenamento, ou redirecionamento para outro modelo de desenvolvimento que não o anterior.

Os desastres não se resumem a fatores apenas externos que atingem a sociedade, é preciso, também, considerar a forma como o modelo de desenvolvimento econômico é conduzido na região. Neste sentido, os desastres constituem-se não como um problema para o desenvolvimento, mas um problema intensificado por este desenvolvimento.

A partir do reconhecimento de que os desastres compõem-se como processos sociais, e em vista da situação de emergência ocorrida em Blumenau, pôdese verificar que o risco vem sendo gestado numa operação de retroalimentação. Nesse contexto, as instituições focalizam investimentos em obras de contenção e em ações engendradas após o sinistro, pouco aplicando antes, em mudanças de atitudes e incremento sociocultural, entre outros aspectos. Assim, constata-se que o modelo de gestão, atrelado ao desenvolvimento socioeconômico, está ampliando a vulnerabilidade e o risco de desastres na região.

Para isso, a gestão integrada e participativa, com coparticipação da população que vive em áreas de risco deve ser o primeiro passo para uma mudança paradigmática. A redução efetiva do risco de desastres é possível a partir do enfrentamento sistêmico e estrutural da vulnerabilidade social.

A literatura que trata da vulnerabilidade tem apontado para uma dinâmica autônoma e específica pertencente à capacidade de resiliência e às habilidades de reconstrução das comunidades locais. Tomando a resiliência como

[...] a capacidade intrínseca de um sistema, de uma comunidade ou de uma sociedade, predispostos a um choque ou estresse, para se adaptar e sobreviver mudando seus atributos não essenciais e se reconstruindo em uma abordagem estrutural e 
sistêmica, necessária para uma avaliação que vá além da redução da vulnerabilidade (MENDES; TAVARES, 2009, p. 1577, tradução desta autora).

Práticas locais e políticas baseadas na articulação de órgãos oficiais de proteção civil são as formas mais efetivas para construção de resiliência comunitárias para desastres naturais.

Espera-se que os desastres traduzam-se em "aprendizado social" e que novos padrões na relação estado/sociedade, indivíduos/meio ambiente sejam estabelecidos. Que, assim, os desastres sejam tomados como oportunidade de mudança paradigmática e de revisão de valores as quais somadas à vontade de atores-chave auxiliem na preparação desta população para o que está por vir.

\section{Referências}

ALMEIDA, L. Q. de; PASCOALINO, A. Gestão de risco, desenvolvimento e (meio) ambiente no Brasil. Um estudo de caso sobre os desastres naturais de Santa Catarina. Disponível em: <www.geo.ufv.br/simposio/simposio/trabalhos/trabalhos.../ 061.pdf $>$. Acesso em: 3 nov. 2009.

ANGIONI, M.; SAMAGAIA, J. Situação dos desabrigados/ atingidos pelo desastre e a assistência (des)organizada. In: FRANK, B.; SEVEGNANI, L. (Org.). Desastre de 2008 no Vale do Itajaí: água, gente e política. Blumenau: Agência de Água do Vale do Itajaí, 2009, p. 138-147.

AUMOND, J. J. et al. Condições naturais que tornam o Vale do Itajaí sujeito aos desastres. In: FRANK, B.; SEVEGNANI, L. (Org.). Desastre de 2008 no Vale do Itajaí: água, gente e política. Blumenau: Agência de Água do Vale do Itajaí, 2009, p. 22-37.

BARCELOS, F. C.; OLIVEIRA, S. M. Novas fontes de dados sobre risco ambiental e vulnerabilidade social. Disponível em: $<$ http://www.anppas.org.br/encontro4/cd/ARQUIVOS/GT11848-561-20080509105611.pdf.> Acesso em: 2 out. 2010.

BUNGE, M. Development and the Environment. In: BYRNE, E. F; PITT, J. C. (Ed.). Technological Transformation: Contextual and Conceptual Implications. Dordrecht: Kluwer Academic Publishers, 1989, p. 285-304.

FRANK, B. Uma história das enchentes e seus ensinamentos. In: FRANK, B; PINHEIRO, A. (Org.). Enchentes na Bacia do Itajaí: 20 anos de experiências. Blumenau: Edifurb, 2003.

IAMАмОТО, M. V. Projeto profissional, espaços ocupacionais e trabalho do assistente social na atualidade. In: CFESS-Conselho Federal de Serviço Social. As atribuições privativas do (a) assistente social em questão. Brasília: CFESS, fev. 2002, p. 13-50
MATTEDI, M. A. As enchentes como tragédias anunciadas: impactos da problemáica ambiental nas situações de emergência em Santa Catarina. 284 f. Tese (Doutorado em Ciências Sociais) - Universidade Estadual de Campinas, 1999.

.A formação de políticas em Blumenau: o caso do problema das enchentes. In: THEIS, I. M.; TOMIO, F. R.; MATTEDI, M. A. (Org.). Novos olhares sobre Blumenau: contribuições críticas sobre seu desenvolvimento recente. Blumenau: Edifurb, 2000, p. 195-230.

MATTEDI, M. A. et al. O desastre se tornou rotina. In: FRANK, B.; SEVEGNANI, L. (Org.). Desastre de 2008 no Vale do Itajaí: água, gente e política. Blumenau: Agência de Água do Vale do Itajaí, 2009, p. 14-21.

MENDES, J. M.; TAVARES, A. Building Resilience to Natural Hazards. Practices and Policies on Governance and Mitigation in the Central Region of Portugal. Safety, Reability and Risk Analysis: Theory, Methods and Applications. Taylor \& Francis Group, London, p. 1577-1584, 2009.

NEGREDO, J. C. de. A Defesa Civil que não se conhece ou que não se vê. In: FRANK, B.; SEVEGNANI, L. (Org.). Desastre de 2008 no Vale do Itajaí: água, gente e política. Blumenau: Agência de Água do Vale do Itajaí, 2009, p. 63-69.

PNUD-Programa de las Naciones Unidas para el Desarrollo. Dirección de Prevención de Crisis y de Recuperación, 2004. Disponível em: 〈http://www.undp.org/cpr/disred/documents/ publications/rdr/execsummary esp.pdf $>$. Acesso em: 12 out. 2011.

REBOUÇAS, G. N; FILARDI, A. C.; VIEIRA, P. F. Gestão integrada e participativa da pesca artesanal: potencialidades e obstáculos no litoral do Estado de Santa Catarina. Ambiente e Sociedade, Anppas, Procam USP, v. 9, n. 2, p. 83-104 jul./dez. 2006.

RIBEIRO, M. J. Sociologia dos desastres. Revista Sociologia, problemas e práticas, Instituto Universitário de Lisboa, CIES/ IUL, n.18, p. 23-43, 1995.

SCHIOCHET, V. A ação governamental frente ao desastre. In: FRANK, B.; SEVEGNANI, L. (Org.). Desastre de 2008 no Vale do Itajaí: água, gente e política. Blumenau: Agência de Água do Vale do Itajaí, 2009, p. 150-155.

SEVEGNANI et al. Gente socorrendo gente. In: FRANK, B.; SEVEGNANI, L. (Org.). Desastre de 2008 no Vale do Itajaí: água, gente e política. Blumenau: Agência de Água do Vale do Itajaí, 2009, p. 110-127.

SIEBERT, C. (Des)controle urbano no Vale do Itajaí. In: FRANK, B.; SEVEGNANI, L. (Org.). Desastre de 2008 no Vale do Itajaí: água, gente e política. Blumenau: Agência de Água do Vale do Itajaí, 2009, p. 40-51. 
VALENCIO, N. Da morte da Quimera à procura de Pégaso: a importância da interpretação sociológica na análise do fenômeno denominado desastre. In: VALENCIO, N. et al. (Org). Sociologia dos desastres: construção, interfaces e perspectivas no Brasil. São Carlos: Rima Editora, 2009.

VALENCIO, N. et al. (Org.). Sociologia dos desastres: construção, interfaces e perspectivas no Brasil. São Carlos: Rima Editora, 2009.

\section{Notas}

1 Um sistema ecossocial (ou socioambiental) pode ser entendido como um ecossistema alterado pela presença de um sistema sociocultural. Difere de um ecossistema natural pelo fato de, para além da obediência a leis naturais, sujeitar-se também a leis ditadas pela expressão de necessidades e aspirações humanas (BUNGE, 1989).

2 A cultura dos desastres define-se como conjunto socialmente produzido de valores, normas, regras e saberes que enquadram as representações, atitudes, comportamentos adotados relativamente às distintas expectativas que decorrem de situações sociais e ambientais específicas (BRITTON, 1992 apud RIBEIRO, 1995).

3 De acordo com Frank (2003), a bacia hidrográfica do rio Itajaí compreende uma área de 15 mil km², dos quais cerca de $80 \%$ encontram-se na região da floresta pluvial da costa atlântica, ou Mata Atlântica, montanhosa e fortemente entrecortada por rios e ribeirões.

4 Em situações de desastres, a atuação dos governos é definida pela situação de excepcionalidade, a qual é legalmente reconhecida em função da gravidade como "estado de calamidade pública (maior gravidade) ou situação de emergência (menor gravidade). [...] Tais institutos legais permitem ao poder público tomar decisões e adotar procedimentos para ampliar e agilizar o atendimento da população atingida (SCHIOCHET, 2009, p. 150).

5 Navegantes é um município do estado Santa Catarina, onde se localiza o Aeroporto Internacional Ministro Victor Konder, considerado a principal porta de entrada para quem mora no Vale do Itajaí e nas proximidades.

6 A Defesa Civil tem, através do Decreto n ${ }^{\circ}$ 5.376, de 17.02.2005, definidas as sua atividades. De acordo com o Art. 2 ,"As ações de defesa civil são articuladas pelos órgãos do SINDEC e objetivam, fundamentalmente, a redução dos desastres, que compreendem os seguintes aspectos globais: I- a prevenção de desastres; II- a preparação para emergências e desastres; III- a resposta aos desastres; IV- a reconstrução e a recuperação. Disponível em: 〈www.defesacivil.gov.br〉. Acesso em: 16 nov. 2011.

7 Benefícios como: auxílio natalidade, auxílio funeral, e pró-renda (que inclui os projetos Renda Cidadã, Renda Associativa e Renda trabalho) foram alguns dos benefícios cancelados. Estes últimos, são programas de transferência de renda mensal repassada às famílias de baixa renda do município.

8 Dados coletadas mediante a técnica de observação participante da autora deste artigo.

9 Informações repassadas por técnicos da prefeitura e por vítimas do desastre.

\section{Rúbia dos Santos}

rubiasantos@furb.br

Doutora em Sociologia Política pela Universidade Federal de Santa Catarina.

Professora no Departamento de Serviço Social da Fundação Universidade Regional de Blumenau (FURB)

\section{FURB - Departamento de Serviço Social}

Rua Antonio da Veiga

Bairro Victor Konder

Blumenau - Santa Catarina

CEP: 89012-900 